\title{
Las dimensiones de la competencia en el sistema de partidos mexicano (1979-2012)
}

\author{
The dimensions of competition in the Mexican \\ party system (1979-2012)
}

\author{
Oniel Francisco Díaz-Jiménez/ o.diaz@correo.ler.uam.mx \\ Universidad Autónoma Metropolitana-Lerma, México \\ IgorVivero-Ávila/ivivero@yahoo.com \\ Universidad Autónoma del Estado de México, México
}

\begin{abstract}
This article focuses on the major transformations in the Mexican party system that occurred during the protracted process of democratic transition; it is divided into three parts. The first part is a brief review of the factors that contributed to the process of political-electoral change. In the second part, we carry out an analysis of changes in a number of dimensions of the Mexican party system, based on aggregate electoral data at national and district levels, as well as on data from public opinion surveys. The third part presents an analysis of the ideological structure of political competitiveness based on data from surveys on the left-right ideological stances of Mexican federal legislators. The paper shows important changes in the structure and behaviour of the Mexican electorate, such as increasing partisan de-alignment, as well as a growing level of competitiveness and fractionalization of the party system.
\end{abstract}

Key words: party system change, partisan de-alignment, electoral volatility, party fractionalization, party system nationalization, left-right ideological positioning.

Resumen: El presente artículo se enfoca en las transformaciones relevantes del sistema mexicano de partidos ocurridas durante el prolongado proceso de transición democrática, y se divide en tres partes: en la primera se hace una breve revisión de los factores que coadyuvaron al cambio político-electoral; en la segunda presentamos un análisis de los cambios en diversas dimensiones del sistema mexicano de partidos, basado en datos electorales agregados a nivel nacional y distrital, así como en datos de encuestas de opinión pública; en la tercera parte se realiza un análisis de la estructura de competencia ideológica del sistema de partidos apoyada en datos de encuestas sobre la autoubicación y la ubicación ideológica en la dimensión izquierda-derecha de los legisladores federales. El trabajo muestra importantes cambios en la estructura y el comportamiento del electorado mexicano, incluyendo un creciente desalineamiento partidista, así como una mayor competitividad y fragmentación del sistema de partidos.

Palabras clave: cambio en el sistema de partidos, fragmentación partidista, volatilidad electoral, nacionalización del sistema de partidos, desalineamiento partidista, ideología izquierda-derecha. 


\section{Introducción $^{1}$}

El objetivo principal de este artículo es realizar un análisis descriptivo acerca del cambio en el sistema mexicano de partidos en el contexto de la prolongada transición de un régimen autoritario de partido dominante hacia un sistema multipartidista competitivo, experimentada desde finales del siglo pasado. Las preguntas centrales del trabajo son cómo ha evolucionado la competencia en el sistema y qué factores explican los cambios en la competencia partidista. Para ello nos centramos en el análisis de dos dimensiones relevantes de la competencia política: la electoral y la ideológica. Los objetivos particulares del trabajo son tres: primero, hacer una breve revisión de los factores que favorecieron el proceso de cambio político-electoral; segundo, presentar un análisis longitudinal de los cambios en diversas dimensiones de la estructura y el comportamiento del electorado mexicano, incluyendo la fragmentación partidista, la nacionalización, la volatilidad electoral y la distribución agregada del partidismo de los electores.

El análisis está sustentado en datos electorales agregados a nivel nacional y a nivel distrital, así como en datos de encuestas de opinión pública. Los cambios en las dimensiones del sistema de partidos se analizan a la luz de la literatura comparada sobre el desalineamiento electoral, entendido como un conjunto de transformaciones en la estructura y el comportamiento del electorado que son comunes a un considerable número de democracias contemporáneas, tanto nuevas como avanzadas (véase Dalton y Wattenberg, 2000; Mair et al., 2004; Sánchez, 2007; Dalton, 2008). Dichos cambios incluyen niveles crecientes de desalineamiento partidista, volatilidad electoral, voto dividido/cruzado, fragmentación partidista, abstencionismo, y apoyo a partidos emergentes (Dalton et al., 1984; Hagopian, 1998).

El tercer objetivo es describir la estructura de competencia ideológica del sistema de partidos, con base en datos de encuestas sobre la autoubicación y la ubicación ideológica en la dimensión izquierda-derecha de los legisladores federales, durante las últimas seis legislaturas, donde ningún partido político tiene la hegemonía electoral ni cuenta con la mayoría absoluta en la Cámara de Diputados, lo cual refleja procesos de intensa competencia y negociación política. La selección del periodo de estudio incluye las etapas de liberalización y democratización del régimen autoritario (Cfr. Labastida Martín del

1 Este trabajo se elaboró con el apoyo del Conacyt para el doctor Vivero a través del programa de "Estancias Posdoctorales y Sabáticas al Extranjero para Consolidación de Grupos de Investigación 2013”. 
Campo y López Leyva, 2004), así como la nueva era competitiva del sistema de partidos.

\section{El cambio electoral en México: del sistema autoritario de partido dominante al competitivo y multipartidista}

La transición democrática mexicana difiere del modelo de transiciones basado en un "pacto de élites" descrito en la literatura pionera sobre democratización (e.g. O’Donnell y Schmitter, 1986; Przeworski, 1991). La principal diferencia de la transición mexicana es su punto de partida. A diferencia de otros regímenes autoritarios completamente cerrados a la competencia política, el régimen posrevolucionario mexicano permitió la existencia de algunas instituciones que caracterizan a sistemas democráticos como: elecciones periódicas, partidos de oposición que participaron regularmente en los procesos electorales y en la conformación de las cámaras legislativas, etc. Tales instituciones proporcionaron un grado considerable de legitimidad y estabilidad al sistema político, a la vez que permitieron la formación y eventual consolidación de un "Régimen Autoritario Competitivo" con el Partido Revolucionario Institucional (PRI) como actor predominante (Levitsky y Way, 2002). ${ }^{2}$

Tras su creación en 1929, el PRI ganó todas las elecciones a gobernador hasta 1989, mantuvo una mayoría en el Congreso hasta 1997, y venció en todas las elecciones presidenciales hasta el año 2000. El caso mexicano fue tal vez el mejor ejemplo de un "Régimen Autoritario de Partido Dominante" (Dominant Party Authoritarian Regime, DPAR), un tipo particular de autoritarismo competitivo que se caracteriza por "el control, tanto del poder ejecutivo como del legislativo, de manera continua por un solo partido durante al menos 20 años o, al menos, cuatro elecciones consecutivas" (Greene, 2007: 12).

2 Levitski y Way (2010b: 57) definen a los Regímenes Autoritarios Competitivos como "regímenes civiles en los cuales las instituciones democráticas formales existen y son ampliamente vistas como los medios principales para obtener y ejercer el poder político. Sin embargo, el abuso de los recursos del Estado por parte de los funcionarios del régimen los coloca en una posición de gran ventaja frente a sus oponentes. Tales regímenes son competitivos debido a que los partidos de oposición usan las instituciones democráticas para competir seriamente por el poder, pero son no democráticos porque el terreno de juego está fuertemente inclinado en favor del oficialismo. La competencia es por lo tanto real pero injusta”. (Para una revisión de las principales características de autoritarismo competitivo, véase Levitski y Way, 2010a.) 
El dominio electoral del PRI, incluso en contextos de graves crisis económicas y una creciente insatisfacción de los votantes con el desempeño económico de los gobiernos priístas durante los años ochenta y noventa, fue posible debido a tres tipos de ventajas que el PRI tenía sobre la oposición: 1) la asimetría entre los recursos del partido gobernante y los de los partidos de oposición como consecuencia del desvío sistemático de fondos públicos para uso electoral (Greene, 2007), posibles debido a: a) la existencia de un gran sector público, $b$ ) la continua presencia del PRI en posiciones del Poder Ejecutivo a nivel federal, estatal y municipal, y $c$ ) una amplia y políticamente permisiva burocracia pública y la falta de un órgano de administración electoral independiente con funciones de supervisión y sanción eficaces (Klesner, 2005; Greene, 2007); 2) ventajas relacionadas con la capacidad del PRI de elevar los costos de unirse a los partidos de oposición, mediante la negación de bienes selectivos de patronazgo a los miembros y activistas de los partidos de oposición, o cuando el sistema de patronazgo del PRI fallaba, mediante represión selectiva contra ellos (Greene, 2007); y 3) ventajas institucionales y legales relacionadas con reglas de competencia electoral que limitaban la competitividad de los partidos de oposición, como un altamente politizado modelo gubernamental de administración electoral, en el cual las elecciones eran organizadas y validadas por el Poder Ejecutivo (Cfr. Molinar, 1991b, 1996; Valdés Zurita, 1995; Becerra et al., 2000; Méndez de Hoyos, 2006).

\section{El surgimiento de la competencia partidista y el declive del partido dominante}

El incremento en la competitividad electoral es una de las dimensiones más relevantes del proceso de cambio político en México y se explica, en parte, debido a la modernización socioeconómica del periodo posterior a la Segunda Guerra Mundial. Los efectos del proceso de modernización del país fueron particularmente importantes durante los años sesenta, setenta y la primera mitad de los ochenta, lo que se tradujo en una tendencia gradual de declive electoral del partido dominante. ${ }^{3}$ Sin embargo, el declive en el rendimiento electoral del PRI se aceleró a finales de los ochenta y noventa (después de

3 Diversos análisis sobre el comportamiento electoral en México (Ames, 1970; Ramos Oranday, 1985; Molinar y Weldon, 1990; Klesner, 1987, 1993, 1994, 1995, 2005; Méndez de Hoyos, 2006) subrayan el papel de factores relacionados con la modernización socioeconómica como: urbanización, industrialización, educación, afluencia económica, entre otros, en el aumento del apoyo electoral para los partidos de oposición y, por lo tanto, en el aumento de la competitividad electoral. 
que el país había alcanzado un grado considerable de desarrollo). Esto sugiere que, aunque la modernización socioeconómica tuvo un impacto significativo en el aumento de la competitividad electoral, otros factores también desempeñaron un papel relevante en el proceso de cambio político. Numerosos estudios han proporcionado evidencia que indica que el aumento de la competencia partidista en los noventa también fue influido por factores relacionados con las reformas electorales promulgadas entre 1990 y 1996, como resultado de las negociaciones entre el PRI y los partidos de oposición. ${ }^{4}$

Las reformas electorales incentivaron el aumento de la competitividad, al nivelar el campo de juego electoral. Éstas contribuyeron a disminuir las ventajas de recursos del partido dominante, al establecer organismos públicos autónomos de administración y supervisión electoral que limitaron el uso de recursos públicos para fines partidistas, y también proporcionaron a los partidos de oposición importantes recursos (tanto financieros como de acceso a medios) para competir contra el PRI.

A pesar de su relevancia, la modernización socioeconómica y el cambio institucional no son suficientes para explicar el declive del rendimiento electoral del PRI durante los años ochenta y noventa. Profundas crisis económicas a mediados de los ochenta, así como las políticas implementadas por los gobiernos priístas, resultado de tales crisis, también tuvieron un papel importante en el declive electoral del partido dominante. Estudios sobre el voto económico en México indican que las evaluaciones económicas retrospectivas sí influyeron en el comportamiento electoral de los mexicanos durante los noventa (Magaloni, 1999; Poiré, 1999; Buendía, 2004).

Sin embargo, estos análisis también muestran que el impacto de esas evaluaciones sobre las decisiones de voto de los mexicanos fue bastante más débil respecto al impacto que éstas usualmente tienen en las democracias establecidas. De acuerdo con la literatura sobre el voto retrospectivo económico (Fiorina, 1981), los partidos en el gobierno tienden a perder elecciones debido a la insatisfacción de los electores con sus resultados en el manejo de la economía. No obstante, en México, el PRI sobrevivió a profundas crisis eco-

4 El estudio de Méndez de Hoyos (2006) sobre los determinantes de la competitividad electoral desde 1997 a 2003 encontró que los factores de modernización socioeconómica fueron importantes predictores del aumento en la competitividad electoral, especialmente hasta finales de los ochenta. Sin embargo, su influencia disminuyó significativamente a partir de 1991. Después de introducir medidas cuantitativas del grado de equidad de las reformas electorales, ella encontró una asociación positiva y significativa entre la equidad y la justicia en las reformas electorales y la competitividad electoral. 
nómicas a mediados de los ochenta. De hecho, estudios basados en encuestas realizadas a finales de los ochenta y principios de los noventa muestran que la intención de voto a favor del PRI siguió siendo alta incluso entre aquellos que expresaron mayor insatisfacción con el rendimiento económico del partido gobernante (Domínguez y McCann, 1996; Buendía, 2004; Magaloni, 2006).

Se han propuesto dos explicaciones diferentes, pero más bien complementarias, sobre la reducción lenta y gradual del apoyo electoral para el partido dominante, incluso después de que el electorado sufrió las consecuencias de severas crisis económicas: la primera se centra en el papel de los votantes para acabar con el dominio del PRI. De acuerdo con Magaloni (2006), el PRI fue capaz de sobrevivir, a pesar de sus malos resultados económicos, debido a que las experiencias acumuladas de los electores, sobre los muchos años de estabilidad y crecimiento económico, mediaban y atemperaban las evaluaciones más recientes sobre el deficiente desempeño económico del PRI. Como resultado, los votantes más jóvenes tendieron a retirarle su apoyo al PRI más rápido que los más viejos, simplemente porque ellos no habían experimentado un largo periodo de crecimiento económico y estabilidad bajo los gobiernos priístas. En cambio, los electores mayores le retiraron su apoyo al partido dominante de manera más gradual, porque tendían a sopesar todos estos años de desarrollo y los más recientes de mala gestión económica de los gobiernos del PRI.

En contraste con las teorías del voto prospectivo, que sostienen que las crisis económicas también proporcionan fuertes incentivos para votar a favor de la oposición, el modelo de Magaloni subraya el papel de la aversión al riesgo de los votantes en el sostenimiento del dominio electoral del PRI, dado que los ciudadanos tendían a temer a la oposición porque carecían de suficiente información sobre el desempeño de los partidos de oposición en el gobierno. Esa falta de información también afectó negativamente la credibilidad del PAN y el PRD en términos de sus ofertas prospectivas de políticas públicas. Magaloni (2006) sostiene que el predominio electoral del PRI llegó a su fin sólo después de la segunda crisis económica de mediados de los noventa, una vez que el peso retrospectivo, de muchos años, de la estabilidad económica tendió a desvanecerse gradualmente, y los electores estuvieron más dispuestos a correr el riesgo de votar por la oposición.

Una explicación alternativa enfatiza el papel de los partidos de oposición y sus estrategias en terminar el dominio electoral del PRI. Según esta perspectiva, las crisis económicas y la posterior respuesta en forma de liberalización económica fomentaron el declive del PRI. Mientras que durante los años ochenta el partido dominante aún gozaba de importantes ventajas 
relacionadas con el acceso a recursos gubernamentales y su posterior uso con fines electorales, la situación cambió sustancialmente en la década de los noventa como resultado de las reformas orientadas al mercado. La privatización de empresas paraestatales privó al PRI de fuentes importantes de patronazgo y de clientelismo para comprar el apoyo de los votantes y para socavar la competitividad de los partidos de oposición. Sin embargo, aun cuando se redujeron significativamente las ventajas en cuanto a recursos del partido dominante y una buena parte del electorado se mostraba crecientemente insatisfecha con su pobre rendimiento económico, la investigación de opinión pública, realizada a finales de los ochenta y principios de los noventa, muestra que los votantes estaban renuentes a votar por la oposición. En contradicción con la primera explicación, donde se sostiene que esto se debe al temor de los electores ante la incertidumbre del gobierno de los partidos de oposición, esta perspectiva no sólo se centra en los cambios en la estructura del electorado mexicano y sus determinantes, sino también en los fallos de los partidos de oposición con el fin de responder al cambio electoral.

De central importancia para esta corriente de análisis fue la transformación de las organizaciones partidarias de oposición de nicho a catch-all, en la desaparición del dominio del PRI y el crecimiento de la competitividad electoral durante la década de 1990 (Greene, 2007). Desde esta perspectiva, el dominio del PRI se prolongó debido a la limitada capacidad organizativa del PAN y PRD para expandir sus bases de apoyo electoral, pese a que la magnitud de las ventajas de recursos del PRI se había reducido considerablemente como resultado de profundos procesos de liberalización política y económica. Tanto el PAN como el PRD estaban demasiado limitados por sus orígenes como organizaciones nicho, caracterizadas por una estrecha vinculación con sus tradicionales bases de apoyo electoral y por "altos obstáculos a la afiliación de nuevos activistas” (Greene, 2007: 208), para tomar ventaja del creciente desalineamiento del electorado respecto del PRI. Estos modelos organizativos desempeñaron un papel clave en la supervivencia de los partidos de oposición en un contexto electoral extremadamente adverso, caracterizado por masivas asimetrías en cuanto a recursos, acceso a medios y a las instituciones del Estado. ${ }^{5}$ Sin embargo, fueron altamente ineficaces en la generación de los

5 De acuerdo con Greene (2007: 208), los modelos de partido nicho fueron diseñados por los fundadores y los primeros activistas de los partidos de oposición, "quienes se unieron a los partidos de oposición de manera temprana cuando las ventajas de recursos y el uso de represión por parte del partido dominante fueron significativos [y] [...] jugaron un papel clave cuando se crearon. Estos eran un importante componente en la formación de partidos de oposición que se distinguieran estrictamente del partido dominante y estuvieron poblados 
cambios organizativos necesarios para apelar a un electorado más centrista, amplio y desalineado respecto del partido dominante.

Pese al declive de las ventajas del PRI, el aumento del financiamiento público para todos los partidos y la creciente apertura de los medios de comunicación durante los ochenta y noventa, una serie de dinámicas organizativas de los partidos de oposición (mecanismos de afiliación de activistas, selección de candidatos, tácticas y estrategias de campaña) siguieron mostrando características de tipo nicho hasta mediados de los noventa (Klesner, 2005; Greene, 2007). Los líderes y militantes que se unieron a los partidos de oposición en sus primeras etapas solían preferir mensajes políticos altamente ideologizados, dirigidos a sus tradicionales bases de apoyo por medio de campañas tradicionales basadas en el contacto directo con los votantes.

Por el contrario, el personal más moderado y pragmático que se unió al PAN y al después de que las ventajas del partido dominante habían disminuido sustancialmente, estaba más dispuesto a realizar mensajes más centristas, dirigidos hacia el electorado en general a través de tácticas y estrategias de campaña basadas en el uso intensivo de medios de comunicación (Greene, 2007). La disminución gradual de las ventajas del PRI y el aumento de la competencia electoral eventualmente incentivaron cambios significativos en las dinámicas de reclutamiento de activistas y élites en los partidos de oposición -así como en su equilibrio interno de poder-, lo cual permitió su gradual transformación desde organizaciones nicho o sectarias, en organizaciones de tipo catch-all capaces de derrotar al partido dominante. No obstante, esta transformación "fue lenta y pausada en parte porque sus organizaciones estaban pobremente diseñadas para la innovación” (Greene, 2007: 208).

\section{Dimensiones de cambio en el sistema de partidos: la dimensión electoral}

\section{Fragmentación y número efectivo de partidos}

A continuación examinaremos algunos de los cambios relevantes en el sistema mexicano de partidos. La Tabla $1^{6}$ muestra los resultados en las elecciones al Congreso federal desde 1979 hasta 2012, incluyendo diversos indicadores

por activistas sumamente comprometidos, quienes tenían más probabilidades de permanecer activos a pesar de los altos costos y los bajos beneficios".

6 Todas las tablas y los gráficos se encuentran en el Anexo, al final del presente texto (Nota del Editor). 
de competitividad, fragmentación, volatilidad electoral y nacionalización del sistema de partidos. Hasta antes de las elecciones de 1988, tanto la competencia como la fragmentación electoral en el sistema de partidos fueron muy limitadas, así lo indican el Índice de Fragmentación (Rae, 1967) ${ }^{7}$ y el del Número de Partidos (NP) (Molinar, 1991a) (Tabla 1). ${ }^{8}$ Desde mediados de los noventa la situación cambió significativamente y ambos indicadores reflejan la transformación en el sistema, desde uno autoritario de partido dominante a uno competitivo. Mientras que el NP promedió 1.2 partidos, de 1979 a 1991, en la elección de 1994, éste indica por primera vez una lógica de competencia entre dos partidos fuertes, a los cuales se agrega un tercero, que es más débil, y a partir de 1997 el NP muestra un formato de competencia tripartidista a nivel nacional (véase Tabla 1 ).

Con el fin de proporcionar una visión más detallada de la configuración del sistema de partidos, a continuación se muestra un análisis del NP a nivel de los 300 distritos uninominales en elecciones al Congreso federal. Los distritos se agrupan de acuerdo con el esquema propuesto por Pacheco Méndez (1997): Sistema de partido dominante: incluye los distritos en los que domina un solo partido ( $\mathrm{NP}=1.0$ a 1.5); Bipartidismo puro: distritos donde dos partidos compiten efectivamente ( $\mathrm{NP}=1.5$ a 2.0); Bipartidismo plural: distritos en que dos partidos compiten y se agrega un tercero, que es más débil $(\mathrm{NP}=2.0$ a 2.5); y Tripartidismo o multipartidismo: distritos en los que tres (o más) partidos compiten (NP > 2.5). El análisis muestra que el PRI mantuvo su posición dominante en el sistema de partidos hasta principios de los

7 El Índice de Fragmentación de Douglas Rae (1993) puede interpretarse como la probabilidad de que al elegir dos electores aleatoriamente, éstos voten a distintos partidos. La fragmentación se calcula mediante la siguiente fórmula: $F=1-\operatorname{suma}\left(\mathrm{v}_{\mathrm{i}}\right)^{2}$, donde $\mathrm{v}_{\mathrm{i}}$ es la proporción de votos de cada partido, sobre un total igual a 1.

8 Se utiliza el índice de NP en lugar del índice del Número Efectivo de Partidos (NEP) (Laakso y Taagepera, 1979) debido a que el NEP presenta problemas y sesgos de medición en sistemas unipartidistas. Frecuentemente indica formatos de competencia multipartidista, aun en situaciones donde la disparidad entre el tamaño de los partidos es tal, que el porcentaje de apoyo recibido por el partido más grande supera $50 \%$ de los votos (es decir, un dominio absoluto de un solo partido) (Taagepera, 1999, 2007). El índice NP se deriva del NEP pero permite corregir la sobrerrepresentación de la fragmentación producido por el NEP, al contar al partido ganador de manera separada del resto de los partidos, asignándole un valor de 1 . La fórmula del Número Efectivo de Partidos es la siguiente: $\mathrm{NEP}=1 / \sum\left(\mathrm{v}_{\mathrm{i}}\right)^{2}=1 /(1 / 1-\mathrm{F})$, donde $\mathrm{v}_{\mathrm{i}}$ es la proporción de votos de cada partido (sobre un total igual a 1 ) y $\mathrm{F}$ el índice de fragmentación. Por su parte, la fórmula de Molinar es la sumatoria del porcentaje de votos al cuadrado (o escaños) a partir del segundo partido más votado más uno. 
noventa. El crecimiento significativo de la fragmentación y la competitividad en el sistema se dio sólo a partir de la elección de 1994, en la cual los distritos con una lógica de partido dominante se redujeron significativamente a sólo un quinto del total (Tabla 2).

Los datos también revelan que, a pesar del sistema nacional de tres partidos, la tendencia dominante durante los noventa y la primera década del nuevo siglo ha sido la competencia bipartidista (entre dos o dos y medio partidos) en la mayoría de los distritos (Tabla 2). Por esta razón, algunos autores han cuestionado que el sistema mexicano pudiera considerarse como verdaderamente tripartidista, argumentando que éste podía ser descrito con mayor precisión como un sistema de tres partidos a nivel nacional, que coexiste con un par de sistemas bipartidistas con fuertes bases regionales, con el PRI y el PAN dominando la competencia, sobre todo en el norte y en la región centro-oeste, y con el PRI y el PRD compitiendo, principalmente, en el sur del país (Pacheco, 1997, 2003; Klesner, 2005). Sin embargo, los datos presentados en este trabajo muestran que la elección de 2012 marcó una diferencia importante respecto a elecciones anteriores, ya que casi dos terceras partes de los distritos tuvieron una competencia multipartidista (Tabla 2). El promedio del NP en estos distritos fue de 3.07 partidos (desviación estándar de 0.45$)$. En resumen, los datos demuestran un aumento significativo de la competencia entre partidos a nivel distrital.

\section{Volatilidad}

Una de las dimensiones más relevantes en la literatura sobre el cambio electoral y los sistemas de partidos está relacionada con el grado de inestabilidad del comportamiento electoral. La volatilidad electoral nos permite observar a los sistemas de partidos desde el punto de vista dinámico, pues nos informa sobre la variación que se registra entre el apoyo electoral hacia los partidos de una elección a la siguiente. Los altos niveles de volatilidad indican una alta disponibilidad del electorado así como una mayor competencia electoral.

Sin embargo, a menudo son también un indicador de bajos niveles de institucionalización de los sistemas de partidos. De acuerdo con estudios comparados sobre volatilidad en América Latina (Roberts y Wibbels, 1999; Payne, 2007) los niveles de volatilidad en México, tanto en elecciones parlamentarias y presidenciales, son similares a los de los países de América Latina, con niveles que van de mínimos a moderados. Aun así, en comparación con las democracias occidentales, los países latinoamericanos (incluyendo a México) exhiben porcentajes de volatilidad promedio, que podrían ser consi- 
derados como muy altos o incluso extremos. Diversos estudios han señalado que la volatilidad en América Latina es considerablemente más alta que en las democracias occidentales establecidas (Roberts y Wibbels, 1999; Mainwaring y Zoco, 2007; Payne, 2007). ${ }^{\text {? }}$

Con el fin de medir la estabilidad de los patrones de competencia interpartidista en México, utilizaremos el índice de volatilidad (Perdersen, 1983), el cual se obtiene de sumar el cambio neto en el porcentaje total de votos que cada partido gana o pierde entre dos elecciones sucesivas y de dividir la cifra resultante entre dos. El rango de valores va desde 0 (ningún cambio) a 100 (cambio total). ${ }^{10}$ La Tabla 1 presenta los niveles de volatilidad electoral en México en cada elección congresional desde 1979 hasta 2012. Los datos muestran que el predominio electoral del PRI también se reflejó en los niveles mínimos de volatilidad hasta las elecciones de 1988, donde la volatilidad total alcanzó $21.85 \%$ (el valor más alto durante el periodo analizado). La volatilidad continuó siendo alta de 1988 a 1994, y promedió 20\%, hecho que refleja la recuperación del PRI y el descenso de los partidos que conformaron el Frente Democrático Nacional (FDN). Pese a que la volatilidad disminuyó gradualmente en elecciones posteriores, ésta nunca ha vuelto a los bajos niveles característicos de las contiendas anteriores a 1988, y se ha mantenido en niveles medios/medios altos.

\section{Nacionalización}

El estudio de la nacionalización de los sistemas de partidos, entendido como el grado de homogeneidad del apoyo hacia los partidos a lo largo del territorio de un país, constituye todavía un vacío en buena parte de la literatura comparada sobre partidos y sistemas de partidos en América Latina. Los es-

9 Por ejemplo, la volatilidad global en las elecciones al Congreso de Estados Unidos ha sido de $3.3 \%$ entre 1946 y 2002, y de $11.2 \%$ en elecciones presidenciales en el periodo 1948 1996; de acuerdo con un estudio reciente sobre cambio electoral en ocho países de Europa occidental, los niveles de volatilidad promedio en todos los casos (con excepción de Italia) fueron inferiores a 12\% durante 1978-2003 (Mair et al., 2004). Por el contrario, los niveles de volatilidad promedio en América Latina durante el mismo periodo han sido superiores a 12\%, en 17 de los 18 países incluidos en el estudio de Payne (2007) sobre sistemas de partidos en AL.

10 La volatilidad se calcula mediante la siguiente fórmula: $\mathrm{Vt}=\sum\left|\left(V_{i 2}-V_{i 1}\right)\right| / 2$, donde $V_{i 1}$ es el porcentaje de votos de un partido en la primera elección, y $V_{i 2}$ el porcentaje de votos del mismo partido en la siguiente elección. 
pecialistas en política en la región se han centrado en diversas dimensiones relevantes de los sistemas de partidos latinoamericanos, tales como la volatilidad (Roberts y Wibbels, 1999; Mainwaring y Zoco, 2007; Payne, 2007), el grado de fragmentación y los problemas de la formación de coaliciones en sistemas multipartidistas (Mainwaring, 1993; Coppedge, 1997; Mainwaring, 1999; Altman, 2000), el nivel de institucionalización (Mainwaring y Scully, 1995; Mainwaring y Torcal, 2005; Payne, 2007; Jones, 2010), y la dimensión ideológica de los sistemas de partidos (Coppedge, 1998; Alcántara Sáez, 2006; Kitschelt et al., 2010).

Sin embargo, no fue sino hasta hace muy poco que el estudio de los sistemas de partidos en la región incluyó la nacionalización del apoyo electoral recibido por los partidos políticos (Jones y Mainwaring, 2003). Anteriormente, una buena parte de la literatura implícitamente presuponía que el apoyo electoral de los partidos era más o menos homogéneo a lo largo del territorio de un país, así como entre las diferentes escalas o niveles institucionales, y que tanto la dinámica como la estructura de competencia en los sistemas de partidos a nivel subnacional simplemente reflejaban las tendencias del nivel nacional (para una discusión amplia sobre el tema, véase Došek, 2011).

Estudios previos basados en el Índice de Nacionalización Partidista (Party Nationalization Score [PNS]) muestran que el caso mexicano exhibe un grado de nacionalización similar al de países de estructura federal y con niveles medios de nacionalización en sus sistemas de partidos, como Estados Unidos y El Salvador (Jones y Mainwaring, 2003). ${ }^{11}$

Este trabajo usa el Índice Estandarizado de Nacionalización Partidista (Standardised Party Nationalization Score [SPNS]) desarrollado por Daniel Bolscher (2010) (basado, al igual que el PNS, en el coeficiente de desigualdad de Gini) como indicador del grado de nacionalización del sistema mexicano de partidos, calculado con base en datos de los 300 distritos electorales uninominales, de 1979 a $2012 .{ }^{12}$ Los valores del índice muestran (con excepción de la elección intermedia de 2003) el considerable grado de nacionalización del sistema mexicano durante el periodo analizado (con va-

11 El estudio señala que aunque estos países están muy lejos de los países con un mínimo grado de nacionalización (por ejemplo: Ecuador y Brasil), se encuentran aún por debajo de los países con altos niveles de nacionalización y estructuras estatales unitarias (por ejemplo: Chile, Costa Rica, Honduras, Jamaica, Nicaragua y Uruguay) (Jones y Mainwaring, 2003).

12 Dicho indicador se deriva del PNS, pero permite mayor comparabilidad entre diversos países y niveles de competencia política y es más adecuado cuando se usan datos relativos a un número alto de subunidades territoriales. 
lores que van de medios-altos a altos), que dan como promedio 0.88 (sPNs) (Tabla 1).

Sin embargo, esto no significa que los principales partidos mexicanos tienen el mismo nivel de nacionalización. El grado de nacionalización del PAN y del PRD es más bajo en comparación con el del PRI, el cual sigue siendo el único partido con una estructura organizativa y base social de apoyo verdaderamente nacionales. Instituciones políticas como el federalismo y la naturaleza descentralizada de la política mexicana contemporánea plantean obstáculos considerables para una mayor nacionalización del sistema de partidos. Según Cantú y Desposato (2012), al final de la etapa de dominio del PRI, la descentralización fiscal (transferencias intergubernamentales que trasladan ingresos provenientes de los impuestos recolectados por el gobierno federal hacia los gobiernos locales) y el fin del control monopólico del PRI sobre las carreras políticas han fortalecido a los actores políticos subnacionales (particularmente a los gobernadores de los estados) a expensas de las élites políticas nacionales.

Como resultado, lo que alguna vez fuera uno de los sistemas más centralizados en el mundo ha dado paso a uno de los más descentralizados, en el cual los cargos públicos subnacionales conllevan poder y recursos considerables. La descentralización de la política mexicana provee fuertes incentivos para que los partidos inviertan sus recursos en estados con elecciones locales. Sin embargo, los partidos de oposición con una base de apoyo regionalizada como el PAN y el PRD concentran sus recursos (provenientes del financiamiento público) y sus estrategias de desarrollo partidista principalmente en aquellos estados donde son electoralmente competitivos, en lugar de canalizar recursos a las entidades en los que sus estructuras organizativas son más bien débiles, con el fin de fortalecerlas y buscar amplio apoyo electoral a nivel nacional (Harbers, 2012).

\section{Cambios en el partidismo: la expansión del mercado electoral}

La presente sección está centrada en dos cuestiones particularmente relevantes respecto al tema de las lealtades partidistas en México. La primera de ellas se refiere a los cambios en la distribución agregada y la fortaleza del partidismo en el tiempo; la segunda muestra los cambios en la influencia de las lealtades partidistas sobre las decisiones de los votantes. Un indicador de las lealtades partidistas en el electorado es la identificación partidista, entendida como una orientación de tipo afectivo que implica simpatía hacia algún partido político en particular (Campbell et al., 1960). 
La identificación partidista tiene dos componentes relevantes: el primero de ellos se refiere a la dirección de la identificación con un partido, y el segundo a la intensidad o fortaleza de dicha identificación (es decir, si el sentimiento de simpatía hacia el partido en cuestión es fuerte o más bien débil). Examinaremos a continuación el primer aspecto. El Gráfico 1 muestra la distribución agregada del partidismo (o macropartidismo) en México de 1983 a 2009.

Como se puede apreciar, la tendencia más clara que surge de los datos es el significativo desalineamiento de los votantes respecto del que fuera el partido dominante. El PRI perdió una cantidad significativa de partidistas durante la mayor parte del periodo examinado, con excepción de algunos breves lapsos de recuperación (1989-1994 y 1997-1999). La proporción del electorado que expresaba identidad partidista priísta cayó de poco más de $50 \%$ en los primeros años de la década de 1980 , a aproximadamente un tercio del electorado a mediados de los noventa.

Una buena parte de la erosión de lealtades hacia el PRI se explica debido al reemplazo generacional. Sin embargo, otra parte se debe a que algunos partidistas desalineados del PRI han cambiado la dirección de su identificación y muchos otros han pasado a engrosar las filas de los apartidistas. ${ }^{13}$ Los niveles de partidismo del periodo que va de 1983 hasta mediados de los noventa reflejan la etapa final del partido dominante, caracterizada por la capacidad del PRI de ganar elecciones con base en la movilización de su partidismo (como probablemente sucedió en las contiendas de 1991 y 1994).

Pero esta etapa también muestra un crecimiento gradual de las lealtades hacia el PAN y de los independientes, segmento que se mantiene como el segundo más numeroso. El periodo que va de 1996 a 2000 revela que, aunque el macropriísmo se mantuvo como la tendencia mayoritaria, continuó también un claro aumento del segmento de independientes así como del panismo. Por su parte, la distribución del partidismo del PRD ha sido la más baja de los tres grandes partidos, lo que da como promedio $12 \%$ durante todo el periodo analizado (Gráfico 1). Los cambios en la distribución del macropartidismo durante este lapso son muy significativos. No es sino hasta la segunda mitad de los noventa, una vez que el priísmo declinó hasta alrededor de un tercio del electorado, que tanto los independientes como los votantes débilmente

13 Diversos estudios (Klesner, 2005; Moreno y Méndez, 2007; Moreno, 2009) señalan que la pérdida de partidistas del PRI se ha correlacionado significativamente tanto con el incremento del segmento de independientes como con el aumento de los identificados con los partidos de oposición, principalmente con el PAN. 
identificados de los tres partidos se volvieron una proporción de votantes lo suficientemente grande para definir el resultado de una elección. A partir de 2000 da inicio otra etapa en la evolución del partidismo en México, en la cual el porcentaje de electores no alineados supera, de manera constante, al macropartidismo del PRI y al de cualquier otra organización partidista, lo cual significa una expansión significativa del mercado electoral respecto al pasado (Gráfico 1).

\section{¿Desalineamiento o realineamiento?}

El desalineamiento, entendido como "el debilitamiento de las lealtades afectivas habituales y estables hacia los partidos entre el electorado" (Norris, 1997: 86), es una tendencia relativamente generalizada en las democracias contemporáneas (tanto viejas como nuevas) donde la mayoría de los ciudadanos ya no se identifican de manera fuerte con los partidos políticos (Dalton et al., 1984; Dalton, 2000, 2008; Mair et al., 2004). En el caso mexicano, los especialistas aún están divididos en cuanto a si los patrones de cambio en la distribución del macropartidismo deben considerarse como evidencia de un desalineamiento o de un realineamiento del electorado mexicano. Existen argumentos válidos en cada lado del debate. Sin duda y contrariamente a la tesis del desalineamiento, en el caso mexicano no todos los partidos han sufrido por igual la pérdida de electores con identificación partidista (como suele suceder en las democracias avanzadas) sino principalmente el PRI, quien tuvo el papel de partido dominante (Moreno, 2003, 2009; Somuano Ventura y Ortega Ortiz, 2003; Klesner, 2005; Moreno y Méndez, 2007). En este sentido, algunos autores sostienen que los cambios en la distribución del macropartidismo en México son el reflejo de una tendencia de realineamiento y que incluso las disminuciones recientes en el número neto de partidistas se relacionan con la continuación del desalineamiento de los votantes respecto del PRI (el cual tuvo su origen en décadas anteriores), y que por lo tanto no deberían ser interpretadas como señales de un desalineamiento generalizado (Moreno, 2009) (véase también Meixueiro, 2014).

Entre los fenómenos que sugieren un posible realineamiento en el sistema mexicano de partidos se encuentran: a) la fuerte correlación entre la reducción del porcentaje de identificados con el PRI y el aumento de la proporción de identificados con el PAN (Moreno y Méndez, 2007; Moreno, 2009), y b) la evidencia de lo que se podría considerar como un fenómeno de realineamiento, denominado "de rotación" y que se refiere a la transferencia de partidistas, no sólo desde el PRI hacia el PAN y hacia el PRD, sino también desde el PAN hacia el PRD y viceversa (Moreno y Méndez, 2007). 
De hecho, la correlación negativa entre el macropanismo y el macroperredismo se ha intensificado a partir de finales de los noventa (Moreno, 2009). Sin embargo, otros estudiosos han argumentado que pese a la evidencia de transferencias de lealtades partidistas desde el PRI hacia los otros dos grandes partidos, un amplio porcentaje del electorado todavía permanece como apartidista, ya que tanto el PAN como el PRD han captado solamente a una limitada proporción del electorado desalineado que procede, no sólo del otrora partido dominante, sino también de la entrada de nuevos votantes jóvenes al mercado electoral (Klesner, 2005). Este argumento se ve reforzado por análisis, más recientes, sobre las variaciones del partidismo a nivel agregado en el periodo que va desde finales de los ochenta a finales de la primera década del siglo Xxi (Moreno, 2009). Tales estudios indican que: a) aunque, en general, el declive del PRI ha beneficiado principalmente al PAN y a los independientes, el desalineamiento se ha intensificado a partir de finales de la década de los noventa (1999), subperiodo en el cual el segmento de independientes ha captado más electores desalineados del PRI que los realineados por el PAN y el PRD, y b) a diferencia de la asociación significativa entre el crecimiento de las lealtades panistas y el aumento de independientes, la evidencia muestra que el crecimiento de los independientes no sólo se correlaciona de manera negativa con la disminución de las lealtades hacia el PRI, sino también, aunque en mucha menor medida, con la pérdida de lealtades hacia el PRD (Moreno, 2009).

Fortaleza del partidismo

La expansión del mercado electoral mexicano no sólo ha implicado profundas transformaciones respecto a la dirección del partidismo de los electores, sino también aspectos importantes relativos a la fortaleza con la cual se expresa ese partidismo. Diversos estudios han demostrado que, al igual que en democracias avanzadas, en México existe una asociación positiva y significativa entre la fortaleza del partidismo y la lealtad del voto (Poiré, 1999; Moreno, 2003, 2009; Klesner, 2004; Flores-Macías, 2009, Somuano, 2014), es decir, entre más fuerte es la identificación partidista de los votantes, mayor es la probabilidad de que éstos voten por los candidatos del partido con el cual se identifican.

Por el contrario, los votantes débilmente identificados, así como los independientes -incluyendo a los inclinados hacia determinado partido (leaners)están más dispuestos a votar por los candidatos de un partido distinto de aquél con el cual se identifican o se sienten más cercanos (Klesner, 2004), y son más 
susceptibles a las dinámicas, a los efectos de las campañas, así como a los factores de corto plazo que influyen sobre el voto (los temas, la personalidad de los candidatos, entre otros). En otras palabras, el aumento en el número de apartidistas y la disminución de los electores con identificación partidista fuerte se traduce en una ampliación del electorado disponible, hacia el cual los partidos y sus candidatos pueden orientar sus estrategias y tácticas de maximización de votos. En México, la proporción de electores con una identificación fuerte hacia algún partido se redujo de aproximadamente un tercio del electorado, a principios de los noventa, a poco más de un quinto durante la primera década del nuevo siglo. El resto de los electores carecen, por lo tanto, de un vínculo fuerte y definitivo con algún partido político (Gráfico 2).

Lealtades partidistas y volatilidad del voto

La relevancia de la identificación partidista en el proceso de cambio electoral depende no sólo de la fuerza del partidismo y de su distribución en el electorado, sino también de su grado de influencia sobre las decisiones de los votantes (Bartels, 2000). Aunque, en general, la identificación partidista ha demostrado ser la variable explicativa más consistente del comportamiento electoral en México (Moreno, 2003, 2009; Somuano y Ortega Ortiz, 2003), algunas investigaciones han proporcionado evidencia de un ligero debilitamiento de la influencia del partidismo sobre el voto (Moreno y Méndez, 2007), así como de sustancial volatilidad individual a finales de la década de 1990 y la primera década del nuevo siglo (Klesner, 2005; Flores-Macías, 2009).

En este sentido, Moreno y Méndez (2007) han mostrado que el porcentaje de voto cruzado (cross-over voting: votos de los identificados con un partido político emitidos por los candidatos presidenciales de otro partido) aumentó de 7\%, en 2000, a 10\% en la elección de 2006. En contraste, el porcentaje de voto normal disminuyó de 65.3 a $59.3 \%$ durante el mismo periodo. Por su parte, el porcentaje de voto dividido (split-ticket voting: votos por candidatos de diferentes partidos políticos en la misma boleta electoral, en lugar de por los candidatos de un sólo partido) también se incrementó de $13 \%$, en 2000 , a $19 \%$, en 2006 . Tales análisis también señalan que el cambio no ha afectado a todos los partidos por igual, ya que el voto cruzado en 2006 fue mayor entre los identificados con el PRI que entre los partidistas de los otros dos grandes partidos, y el voto dividido fue también mayor entre los partidistas del PRI que entre los del PAN y el PRD en ambas elecciones (Moreno y Méndez, 2007). 
Consecuencias de los cambios en el macropartidismo

¿Cuáles son las consecuencias de los cambios en la distribución y la fortaleza del partidismo para el comportamiento de los partidos y candidatos en México? Si bien aún es incierto el grado de desalineamiento o realineamiento del electorado mexicano, una cosa es segura, los partidos no pueden depender sólo de sus propias bases de apoyo para ganar elecciones. Considerando que los votantes que tienen una fuerte identificación partidista son mucho menos susceptibles a las dinámicas de campaña y a las estrategias partidistas, y que nada menos que esto deja considerablemente más espacio a la competencia partidista, se puede afirmar que, en el caso mexicano, ambos: los electores no alineados y los débilmente identificados, constituyen un mercado electoral altamente disponible, así como una proporción de votantes lo suficientemente grande para definir el resultado de una elección.

Puesto que en la mayor parte de la década de 1990 y en lo que va del nuevo siglo hay más votantes independientes y menos votantes fuertemente identificados respecto a décadas anteriores, los tres principales partidos se han visto obligados, cada vez más, a apelar a los votantes débilmente identificados y a los independientes para generar coaliciones electorales ganadoras por medio de estrategias electorales de tipo catch-all, que tienden a priorizar aspectos relativos a la imagen de los candidatos, los temas y las evaluaciones de tipo retrospectivo, entre otros factores de corto plazo que influyen sobre el voto, por encima de las etiquetas partidistas (Klesner, 2005).

Estudios influyentes sobre el cambio y la adaptación de los partidos al desalineamiento electoral en las democracias occidentales consideran la erosión de las lealtades partidistas como una expansión del mercado electoral que genera fuertes incentivos para el cambio organizativo en los partidos, ya que disminuye la bases tradicionales de apoyo electoral de las que estos solían depender (Dalton y Wattenberg, 2000; Mair et al., 2004). Diversos autores (Dalton et al., 1984; Hagopian, 1998) señalan también que el desalineamiento partidista eventualmente puede transformarse en un desalineamiento electoral, caracterizado por niveles crecientes de fragmentación y volatilidad electoral, así como un aumento en las tasas de voto cruzado/ dividido, abstencionismo y apoyo a terceros partidos. 


\section{Dimensiones de cambio en el sistema de partidos: la dimensión ideológica}

\section{Estructuración ideológica del sistema de partidos mexicano}

Este apartado se enfoca en la estructura de competencia ideológico-programática del sistema mexicano de partidos. Siguiendo a Sani y a Sartori (1980/2000), la dimensión que se utiliza para el análisis de tal estructura es el continuum izquierda-derecha. Esta dimensión de competencia espacial (Downs, 1957), dentro de la cual compiten el PAN, el PRI y el PRD, puede ser medida a través de las actitudes y percepciones expresadas por los diputados de los tres partidos en las encuestas del Proyecto de Élites Latinoamericanas (PELA) de los años que comprenden la LVI (1994-1997), LVII (1997-2000), LVIII (2000-2003), LIX (2003-2006), LX (2006-2009) y LXI (2009-2012) legislaturas de México. La dimensión izquierda-derecha es altamente relevante para entender las dinámicas de competencia interpartidista en México, dado que, al igual que en otros sistemas de partidos, ésta "constriñe y condiciona la competición y la cooperación entre los partidos políticos" (Llamazares y Sandell, 2001: 48).

Asimismo, los cambios en las actitudes de los legisladores mexicanos han recibido poca atención en las últimas décadas (Weldon, 2006). Si bien es cierto que una gran parte de las acciones estratégicas de los partidos mexicanos se guían por el pragmatismo, también lo es que dichas acciones son fuertemente influidas por la estructura de competencia ideológico-programática en la cual éstos se desenvuelven.

La vigencia de las categorías izquierda y derecha radica, como lo mencionan Sani y Montero (1986: 155), en que éstas permiten a los actores políticos simplificar el universo político. Además, como lo señalan estos autores, el uso de tales categorías "indica que algo está situado en uno u otro extremo del continuum, o en algún lugar intermedio, es tanto como dotar al objeto de una 'identidad política' y establecer relaciones de proximidad o distancia con otros elementos políticos" (Sani y Montero, 1986: 155).

Es importante resaltar que estas imágenes de izquierda y derecha no son precisas y que gracias a esta ambigüedad se da flexibilidad a los conceptos, con lo que se hace posible entenderlos para incluir en ellos nuevos contenidos y acomodarles así a nuevas circunstancias. Como argumenta Kitschelt (1994, 2001), la dimensión ideológica es importante para entender las dinámicas de los sistemas de partidos. Sin embargo, el contexto donde se desenvuelve 
la competencia ideológica contemporánea no es el tradicional de la bipolaridad producto de la Guerra Fría. Los valores en las sociedades "modernas" se han transformado y esto ha llevado a nuevos temas de la agenda política. Por ejemplo, Alcántara (1995) ha mostrado que es válida la diferenciación izquierda-derecha en América Latina, aun cuando el uso de esta dimensión se quiso encasillar en una interpretación eurocéntrica.

En este sentido, algunos estudios advierten que sería erróneo asumir que las etiquetas de izquierda-derecha en América Latina tienen un significado de tipo económico en todos los países latinoamericanos (Zechmeister y Corral, 2010). ${ }^{14}$ Las investigaciones sobre el tema han identificado tres dimensiones distintas capaces de ser reconocidas como de izquierda-derecha en los países de la región, incluyendo: 1) el grado de intervención económica del Estado, 2) el papel de la Iglesia en la política, y 3) las actitudes hacia el autoritarismo y la democracia (Llamazares y Sandell, 2001). La Tabla 3 muestra la autoubicación de los diputados mexicanos y la escala que le asignaron a sus partidos dentro de la dimensión izquierda-derecha, así como el grado de homogeneidad ideológica durante un periodo de seis legislaturas (1994-2012).

De los datos anteriores se deduce que los entrevistados del PAN, PRI y PRD tienen variaciones importantes respecto a su autoubicación ideológica y a la que le dan a su partido. En ese sentido, el PRD es el que se sitúa más a la izquierda del continuo ideológico. El PRI se mueve por momentos en el centro izquierda (4.71), según la autoubicación, y al centro derecha cuando se trata de ubicar al partido (5.61). Las opiniones de los diputados del PAN son más moderadas cuando se trata de la autoubicación en comparación con el momento de situar al partido; en ese sentido se recorre a la derecha. En suma, salvo los diputados del PRD, los entrevistados se encuentran en una posición moderada respecto a la de su partido. Los datos también muestran que los tres principales partidos políticos en México han experimentado una competencia predominantemente centrípeta.

No obstante, podemos apreciar comportamientos diferenciados, posiblemente influidos por el contexto político-electoral donde fueron electos los diputados federales entrevistados. El PRI, por ejemplo, parece ser el partido que menos distancia guarda en sus opiniones entre la autoubicación que hacen sus legisladores y la que le dan a su partido, a través del tiempo, ubi-

14 Zechmeister y Corral (2010: 6) han mostrado que en algunos países el apoyo a un papel más activo del Estado en la política económica no se reconoce como una posición de izquierda; así como tampoco las actitudes favorables hacia el libre comercio se traducen necesariamente en un posicionamiento de derecha. 
cándose consistentemente en el centro derecha en 2000 y 2003, por lo que representan oposición. Por el contrario, el PRD tiene cambios significativos en sus opiniones y podemos apreciar un partido más a la izquierda en 2006 (el proceso electoral más polarizado que se ha vivido hasta el momento) y una posición más centrista en 2009.

Por su parte, el PAN se desplaza hacia la derecha del continuo ideológico con una posición más centrista con la victoria del gobierno federal en 2000. El partido que tiene doble competencia es el PRI pues, por un lado, contiende en el centro izquierda con el PRD y, por el otro, el centro derecha, con el PAN (Gráfico 3). También es importante destacar que los partidos con una mayor cercanía ideológica son el PRI y el PAN, lo que puede ayudar en la interpretación acerca de por qué han logrado, en el ámbito legislativo, una alta coincidencia que permitió las reformas liberales (en el tema económico) en las últimas dos décadas.

Finalmente, cabe señalar que la izquierda mexicana, por ejemplo, se caracteriza por ser más estatista en el plano económico, más desconfiada hacia las instituciones electorales y más liberal en los aspectos morales (Vivero, 2006), lo cual contribuye al argumento de que el sistema de partidos mexicano presenta una estructura de competencia ideológica y programática, marcada principalmente por el clivaje estatismo-liberalismo económico. ${ }^{15}$

\section{Resultados y conclusiones}

El cambio político-electoral en México fue un proceso largo, complejo e involucró diversos factores (modernización socioeconómica, cambios en la economía, liberalización económica, reformas electorales, cambios en la organización y las estrategias electorales de los partidos de oposición, entre otros). El análisis longitudinal de diversas dimensiones relevantes del sistema de partidos muestra claramente la transición de un sistema autoritario de partido dominante hacia uno más democrático y competitivo, caracterizado por una creciente fragmentación, tanto a nivel nacional como distrital. Uno de los principales hallazgos de este trabajo es que la competencia partidista en los 300 distritos uninominales en elecciones al Congreso federal se acentuó

15 Otros estudios han profundizado en la dimensión ideológica del sistema de partidos, considerando las actitudes tanto a nivel de élites como de electores (para un análisis a profundidad de la dimensión de competencia ideológica en el sistema mexicano de partidos, véase Moreno, 2009; y para un análisis en perspectiva comparada con otros casos en América Latina, véase Alcántara, 2004). 
significativamente durante el proceso electoral de 2012, ya que, por primera vez, la mayoría de los distritos mostraron un formato multipartidista, hecho que no sucedió en las elecciones anteriores, independiente de las alternancias que se experimentaron. Este dato no es menor, sobre todo si se considera que, pese al tripartidismo nacional y en el Congreso, el formato de competencia partidista a nivel distrital que ha prevalecido durante la mayor parte de los noventa y la primera década del nuevo siglo es el bipartidismo. El aumento del número de distritos con competencia efectiva entre tres o más partidos sugiere que el sistema de partidos puede estar gradualmente evolucionando hacia un sistema realmente multipartidista (moderado).

Sin embargo, otros estudios también muestran las dificultades que enfrentan los principales partidos de oposición con una base de apoyo regionalizada (el PAN y el PRD), en un sistema político altamente descentralizado, para fortalecer sus estructuras organizativas locales en el sur y en el norte del país, respectivamente, con el fin de buscar apoyo electoral a nivel nacional, lo cual podría limitar una mayor fragmentación y nacionalización del sistema de partidos. A pesar de que el sistema exhibe un considerable grado de nacionalización, aún existen diferencias significativas entre el grado de homogeneidad del apoyo electoral recibido por los partidos a través del país. El PAN y el PRD siguen teniendo un menor nivel de nacionalización en comparación con el PRI.

Los datos presentados sobre la evolución de la competencia en el sistema de partidos mexicano durante los últimos 30 años sugieren una relación significativa entre el aumento de la competencia partidista con los cambios en la distribución agregada del partidismo de los electores, particularmente con el proceso de desalineamiento. Como se mostró en este trabajo, quienes tienen una débil identificación partidista y quienes no sienten cercanía con algún partido político son la gran mayoría de los electores.

La debilidad de las lealtades partidistas entre el electorado incentiva la volatilidad electoral (sobre todo a nivel individual), y esto ha tenido, a su vez, importantes consecuencias para la competencia política y la configuración actual del sistema de partidos. Aunque la evidencia no es concluyente, y habría que corroborar si las tendencias mostradas se mantienen en el largo plazo, los datos presentados sugieren que los cambios observados en diversas dimensiones del sistema de partidos podrían ser parte de un proceso más amplio de desalineamiento electoral, similar al observado en un número considerable de democracias alrededor del mundo, tanto consolidadas como emergentes, caracterizado por niveles crecientes de desalineamiento partidis- 
ta, volatilidad electoral, voto dividido/cruzado y fragmentación partidista, etc. (Dalton et al., 1984; Hagopian, 1998).

Otra de las evidencias empíricas se da en la dimensión ideológica del sistema, medida a través del continuum izquierda-derecha. En contraste con las opiniones que sostienen que "todos los partidos son iguales", afirmamos, con estos datos, que los partidos mexicanos compiten por un espacio ideológico en el ámbito legislativo, lo cual permite que las afinidades o distancias dentro del continuo izquierda-derecha aprueben, en ciertos temas, formar "alianzas" legislativas, como la que han sostenido el PAN y el PRI en políticas liberalizadoras, principalmente en el tema económico. La competencia ideológica dentro del sistema de partidos es centrípeta, lo que también ha permitido que la distancia ideológica pueda ser salvada y, en ciertas coyunturas, tener alianzas PAN-PRD, como la que se vivió en la legislatura de 1997-2000.

En suma, los hallazgos del trabajo son una aportación dentro de la discusión del cambio en el sistema de partidos mexicano, en el cual una compleja configuración de diversos factores políticos, económicos y sociales derivó en una creciente competitividad electoral. A su vez, los partidos políticos se han adaptado a un mercado electoral cada vez más competitivo, mediante la introducción de cambios en sus estructuras organizativas, particularmente en sus mecanismos de selección de candidatos, en sus tácticas y estrategias de campaña y en las propuestas de políticas públicas que presentan a los electores. Sin embargo, una buena parte de esos temas constituyen una agenda de investigación aún por desarrollar en la literatura sobre partidos y sistemas de partidos en México.

\section{Bibliografía}

Alcántara Sáez, Manuel (2006), Politicos y politica en América Latina, Madrid: Fundación Carolina, Siglo XxI.

Alcántara Sáez, Manuel (2004), ¿Instituciones o máquinas ideológicas? Origen, Programa y Organización de los Partidos Políticos Latinoamericanos, Barcelona: ICPS.

Alcántara Sáez, Manuel [dir.] (1994-2005), Proyecto de Élites Parlamentarias Latinoamericanas (PELA), Universidad de Salamanca, CICTY, SEC 2002-03483 / CICTY, SEC 19950845 .

Altman, David (2000), "The Politics of Coalition Formation and Survival in Multiparty Presidential Democracies: The Case of Uruguay, 1989-1999”, en Party Politics, vol. 6, núm. 3, United Kingdom.

Ames, Barry (1970), "Bases of Support for Mexico's Dominant Party", en The American Political Science Review, vol. 64, núm. 1, Michigan. 
Bartels, Larry M. (2000), "Partisanship and Voting Behavior, 1952-1996", en American Journal of Political Science, vol. 44, núm. 1, Michigan.

Becerra, Ricardo, Pedro Salazar y José Woldenberg (2000), La Mecánica del Cambio Político en México: Elecciones, Partidos y Reformas, Ciudad de México: Cal y Arena.

Bochsler, Daniel (2010), "Measuring party nationalisation: A new Gini-based indicator that corrects for the number of units”, en Electoral Studies, vol. 29, núm. 1, Essex.

Buendía, Jorge (2004), “The Changing Mexican Voter, 1991-2000”, en Kevin J. Middlebrook [comp.], Dilemmas of Political Change in Mexico, San Diego CA: Institute of Latin American Studies, University of London / Center for U.s.-Mexican Studies, University of California San Diego.

Campbell, Angus et al. (1960), The American Voter, New York; London: John Wiley.

Cantú, Francisco y Scott Desposato (2012), “The New Federalism of Mexico's Party System”, en Journal of Politics in Latin America, vol. 4, núm. 2, Hamburgo.

Coppedge, Michael (1997), "District Magnitude, Economic Performance, and PartySystem Fragmentation in Five Latin American Countries", en Comparative Political Studies, vol. 30, núm. 2, usA: Minnesota.

Coppedge, Michael (1998), “The Dynamic Diversity of Latin American Party Systems”, en Party Politics, vol. 4, núm. 4, United Kingdom.

Cornelius, Wayne A. (2004), "Mobilized Voting in the 2000 Elections: The Changing Efficacy of Vote Buying and Coercion in Mexican Electoral Politics", en Jorge I. Domínguez y Chappell Lawson [comps.], Mexico's Pivotal Democratic Election: Candidates, Voters, and the Presidential Campaign of 2000, Stanford, CA: Stanford University Press.

Craig, Ann L. y Wayne A. Cornelius (1995), “Houses Divided: Parties and Political Reform in Mexico", en Scott Mainwaring y Timothy Scully [comps.], Building Democratic Institutions: Party Systems in Latin America, Stanford, CA: Stanford University Press.

Dalton, Russell J. (2000), “The Decline of Party Identifications”, en Russell J. Dalton y Martin P. Wattenberg [comps.], Parties Without Partisans: Political Change in Advanced Industrial Democracies, Oxford: Oxford University Press.

Dalton, Russell J. (2008), Citizen Politics: Public Opinion and Political Parties in Advanced Industrial Democracies, Washington, DC: CQ Press.

Dalton, Russell J. et al. (1984), Electoral Change in Advanced Industrial Democracies: Realignment or Dealignment?, Princeton, NJ: Princeton University Press.

Dalton, Russell J. y Martin P. Wattenberg [comps.] (2000), Parties Without Partisans: Political Change in Advanced Industrial Democracies, Oxford: Oxford University Press.

Domínguez, Jorge I. y James A. McCann (1996), Democratizing Mexico: Public Opinion and Electoral Choices, Baltimore, MD: Johns Hopkins University Press.

Došek, Tomáš (2011), "La nacionalización de los sistemas de partidos en América Latina: explorando diversos índices de medición”, Ponencia preparada para el x Congreso de la Asociación Española de Ciencia Política y de Administración: "La política en la red", Murcia, 7-9 de septiembre. 
Fiorina, Morris P. (1981), Retrospective Voting in American National Elections, New Haven, Ст: Yale University Press.

Flores-Macías, Francisco (2009), "Electoral Volatility in 2006”, en Jorge I. Domínguez, Chappell H. Lawson y Alejandro Moreno [comps.], Consolidating Mexico's Democracy: The 2006 Presidential Campaign in Comparative Perspective, Baltimore, MD: Johns Hopkins University Press.

Greene, Kenneth F. (2007), Why Dominant Parties Lose: Mexico's Democratization in Comparative Perspective, Cambridge: Cambridge University Press.

Harbers, Imke (2014), "States and strategy in new federal democracies: Competitiveness and intra-party resource allocation in Mexico", en Party Politics, vol. 20, núm. 6, United Kingdom.

Hagopian, Frances (1998), "Democracy and Political Representation in Latin America in the Pause, Reorganization, or Decline?”, en Felipe Agüero y Jeffrey Stark [comps.], Fault Lines of Democracy in Post-Transition Latin America, Coral Gables, FL: NorthSouth Center Press / University of Miami.

Jones, Mark P. (2010), "Beyond the Electoral Connection: The Effect of Political Parties on the Policymaking Process”, en Carlos Scartascini, Ernesto Stein y Mariano Tommasi [comps.], How Democracy Works: Political Institutions, Actors, and Arenas in Latin American Policymaking, Washington, DC: Inter-American Development Bank/ DRCLAS-Harvard University.

Jones, Mark P. y Scott Mainwaring (2003), “The Nationalization of Parties and Party Systems: An Empirical Measure and an Application to the Americas", en Party Politics, vol. 9, núm. 2, United Kingdom.

Kitschelt, Herbert et al. [comps.] (2010), Latin American party systems, Cambridge: Cambridge University Press.

Klesner, Joseph L. (1987), "Changing Patterns of Electoral Participation and Official Party Support in Mexico", en Judith Gentleman [comp.], Mexican Politics in Transition, Boulder, CO: Westview.

Klesner, Joseph L. (1993), "Modernization, Economic Crisis, and Electoral Alignment in Mexico”, en Mexican Studies/Estudios Mexicanos, vol. 9, núm. 2, California.

Klesner, Joseph L. (1994), "Realignment or Dealignment? Consequences of Economic Crisis and Restructuring for the Mexican Party System”, en Maria Lorena Cook, Kevin J. Middlebrook y Juan Molinar Horcasitas [comps.], The Politics of Economic Restructuring: State-Society Relations and Regime Change in Mexico, San Diego, CA: Center for U.S.-Mexican Studies, University of California.

Klesner, Joseph L. (1995), “The 1994 Mexican Elections: Manifestation of a Divided Society?”, en Mexican Studies/Estudios Mexicanos, vol. 11, núm. 1, California.

Klesner, Joseph L. (2004), "The Structure of the Mexican Electorate: Social, Attitudinal, and Partisan Bases of Vicente Fox's Victory”, en Jorge I. Domínguez y Chappell Lawson [comps.], Mexico's Pivotal Democratic Election: Candidates, Voters, and the Presidential Campaign of 2000, Stanford, CA: Stanford University Press.

Klesner, Joseph L. (2005), "Electoral Competition and the New Party System in Mexico", en Latin American Politics \& Society, vol. 47, núm. 2, USA: Miami. 
Convergencia Revista de Ciencias Sociales, núm. 68, 2015, Universidad Autónoma del Estado de México

Laakso, Markku y Rein Taagepera (1979), "Effective Number of Parties: A Measure with Application to Western Europe”, en Comparative Political Studies, vol. 12, núm. 1, USA: Minnesota.

Labastida Martín del Campo, Julio y Miguel Armando López Leyva (2004), “México: una transición prolongada (1988-1996/97)”, en Revista Mexicana de Sociología, vol. 66, núm. 4, México.

Levitsky, Steven y Lucan Way (2010a), Competitive Authoritarianism: Hybrid Regimes after the Cold War, New York: Cambridge University Press.

Levitsky, Steven y Lucan Way (2010b), “Why Democracy Needs a Level Playing Field”, en Journal of Democracy, vol. 21, núm. 1, USA: Washington.

Levitsky, Steven y Luncan Way (2002), “The Rise of Competitive Authoritarianism”, en Journal of Democracy, vol. 13, núm. 2, USA: Baltimore.

Llamazares, Iván y Rickard Sandell (2001), "Partidos políticos y dimensiones ideológicas en Argentina, Chile, México y Uruguay. Esbozo de un análisis espacial”, en Polis, número extraordinario, México.

Magaloni, Beatriz (1999), "Is the PRI Fading? Economic Performance, Electoral Accountability, and Voting Behavior in the 1994 and 1997 Elections", en Jorge I. Domínguez y Alejandro Poiré [comps.], Toward Mexico's Democratization: Parties, Campaigns, Elections, and Public Opinion, London: Routledge.

Magaloni, Beatriz (2006), Voting for Autocracy: Hegemonic Party Survival and its Demise in Mexico, Cambridge: Cambridge University Press.

Mainwaring, Scott (1993), "Presidentialism, Multipartism, and Democracy: The Difficult Combination”, en Comparative Political Studies, vol. 26, núm. 2, usA: Michigan.

Mainwaring, Scott (1999), Rethinking Party Systems in The Third Wave of Democratization: The Case of Brazil, Stanford, CA: Stanford University Press.

Mainwaring, Scott y Timothy Scully [comps.] (1995), Building Democratic Institutions: Party Systems in Latin America, Stanford, CA: Stanford University Press.

Mainwaring, Scott y Mariano Torcal (2005), "Party System Institutionalization and Party System Theory after the Third Wave of Democratization", en Working Paper \#319, Notre Dame, Indiana: The Helen Kellogg Institute for International Studies / University of Notre Dame.

Mainwaring, Scott y Edurne Zoco (2007), "Political Sequences and the Stabilization of Interparty Competition: Electoral Volatility in Old and New Democracies", en Party Politics, vol. 13, núm. 2, United Kingdom.

Mair, Peter, Wolfgang C. Müller y Fritz Plasser [comps.] (2004), Political Parties and Electoral Change: Party Responses to Electoral Markets, London: Sage.

Meixueiro, Gustavo (2014), "Los electores independientes en México en 2006 y 2012", en Gustavo Meixueiro y Alejandro Moreno [comps.], El comportamiento electoral mexicano en las elecciones de 2012, México D.F.: Centro de Estudios Sociales y de Opinión Pública de la Cámara de Diputados.

Méndez de Hoyos, Irma (2006), Transición a la Democracia en México: Competencia Partidista y Reformas Electorales 1977-2003, México: Fontamara. 
Oniel Francisco Díaz-Jiménez e Igor Vivero-Ávila. Las dimensiones de la competencia en el sistema de partidos mexicano (1979-2012)

Molinar, Juan (1991a), "Counting the Number of Parties: An Alternative Index", en The American Political Science Review, vol. 85, núm. 4, Michigan.

Molinar, Juan (1991b), El Tiempo de la Legitimidad: Elecciones, Autoritarismo y Democracia en México, México: Cal y Arena.

Molinar, Juan (1996), "Changing the Balance of Power in a Hegemonic Party System: The Case of Mexico”, en Arend Lijphart y Carlos H. Waisman [comps.], Institutional Design in New Democracies: Eastern Europe and Latin America, Boulder, Co: Westview.

Molinar, Juan y Jeffrey Weldon (1990), “Elecciones de 1988 en México: Crisis del Autoritarismo", en Revista Mexicana de Sociología, vol. 52, núm. 4, México.

Moreno, Alejandro (2003), El Votante Mexicano: Democracia, Actitudes Politicas y Conducta Electoral, México: Fondo de Cultura Económica.

Moreno, Alejandro (2009), La Decisión Electoral: Votantes, Partidos y Democracia en México, México: Miguel Ángel Porrúa.

Moreno, Alejandro (2012), “Who Is the Mexican Voter?”, en Roderic A. Camp [comp.], The Oxford handbook of Mexican politics, Oxford: Oxford University Press.

Moreno, Alejandro y Patricia Méndez (2007), "Identificación Partidista en las Elecciones Presidenciales en México: 2000 y 2006”, en Politica y Gobierno, vol. 14, núm. 1, México.

Norris, Pippa (1997), Electoral change in Britain since 1945, Oxford: Blackwell.

O’Donnell, Guillermo A. y Philippe C. Schmitter (1986), Transitions from Authoritarian Rule. Tentative Conclusions about Uncertain Democracies, Baltimore, MD: Johns Hopkins University Press.

Pacheco Méndez, Guadalupe (1997), “Un Caleidoscopio Electoral: Ciudades y Elecciones en México, 1988-1994”, en Estudios Sociológicos, vol. Xv, núm. 44, México.

Pacheco Méndez, Guadalupe (2003), “Democratización, Pluralización y Cambios en el Sistema de Partidos en México, 1991-2000”, en Revista Mexicana de Sociología, vol. 65, núm. 3, México.

Payne, J. Mark (2007), "Party Systems and Democratic Governability”, en J. Mark Payne, Daniel Zovatto G. y Mercedes Mateo Díaz [comps.], Democracies in Development: Politics and Reform in Latin America, Washington D.C.: Inter-American Development Bank and International.

Pedersen, Mogens N. (1983), "Changing Patterns of Electoral Volatility in European Party Systems: 1948-1977: Explorations and Explanations”, en Hans Daalder y Peter Mair [comps.], Western European Party Systems: Continuity and Change, Thousand Oaks, CA: Sage.

Poiré, Alejandro (1999), "Retrospective Voting, Partisanship, and Loyalty in Presidential Elections: 1994”, en Jorge I. Domínguez y Alejandro Poiré [comps.], Toward Mexico’s Democratization: Parties, Campaigns, Elections, and Public Opinion, London: Routledge.

Przeworski, Adam (1991), Democracy and the Market: Political and Economic Reforms in Eastern Europe and Latin America, Cambridge: Cambridge University Press.

Rae, Douglas W. (1967), The Political Consequences of Electoral Laws, New Haven: Yale University Press. 
Ramos Oranday, Rogelio (1985), "Oposición y Abstencionismo en las Elecciones Presidenciales, 1964-1982”, en Jorge Alonso y Pablo González Casanova [comps.], Las Elecciones en México: Evolución y Perspectivas, México: Siglo XXI.

Roberts, Kenneth M. y Erik Wibbels (1999), "Party Systems and Electoral Volatility in Latin America: A Test of Economic, Institutional, and Structural Explanations”, en The American Political Science Review, vol. 93, núm. 3, UsA: Michigan.

Sánchez, Fernando F. (2007), Partidos Politicos, Elecciones y Lealtades Partidarias en Costa Rica: Erosión y Cambio, Salamanca: Ediciones Universidad de Salamanca.

Sani, Giacomo y José Ramón Montero (1986), "El espectro político: Izquierda, derecha y centro”, en Juan J. Linz y José Ramón Montero Gibert [comps.], Crisis y cambio: electores y partidos en la España de los años ochenta, Madrid: Centro de Estudios Constitucionales.

Sartori, Giovanni (1976), Parties and Party Systems: A Framework for Analysis, Cambridge: Cambridge University Press.

Somuano Ventura, María Fernanda y Reynaldo Yunuen Ortega Ortiz (2003), "La Identificación Partidista de los Mexicanos y el Cambio Electoral, 1994-2000", en Foro Internacional, vol. XLIII, núm. 171, México.

Somuano Ventura, María Fernanda (2014), "Las identidades partidistas de los mexicanos y la eleccion de 2012", en Gustavo Meixueiro y Alejandro Moreno [comps.], El comportamiento electoral mexicano en las elecciones de 2012, México D.F.: Centro de Estudios Sociales y de Opinión Pública/ Cámara de Diputados.

Taagepera, Rein (1999), "Supplementing the effective number of parties", en Electoral Studies, vol. 18, núm. 4, Essex.

Taagepera, Rein (2007), Predicting Party Sizes: The logic of simple electoral systems, Oxford: Oxford University Press.

Valdés Zurita, Leonardo (1995), “El Efecto Mecánico de la Fórmula Electoral Mexicana: 1964-1991”, en Polis, núm. 94, México.

Vivero Ávila, Igor (2006), Desafiando al Sistema: La Izquierda Política en México: Evolución Organizativa, Ideológica y Electoral del Partido de la Revolución Democrática (19892005), México: Universidad Autónoma del Estado de México, Miguel Ángel Porrúa.

Weldon, Jeffrey (2006), “Poder Legislativo. Tiempos de cambio”, en Este País, núm. 181, México.

Zechmeister, Elizabeth y Margarita Corral (2010), "El variado significado de 'izquierda' y 'derecha' en América Latina”, en Perspectivas desde el Barómetro de las Américas. Vanderbilt University, núm. 38, Nashville. 


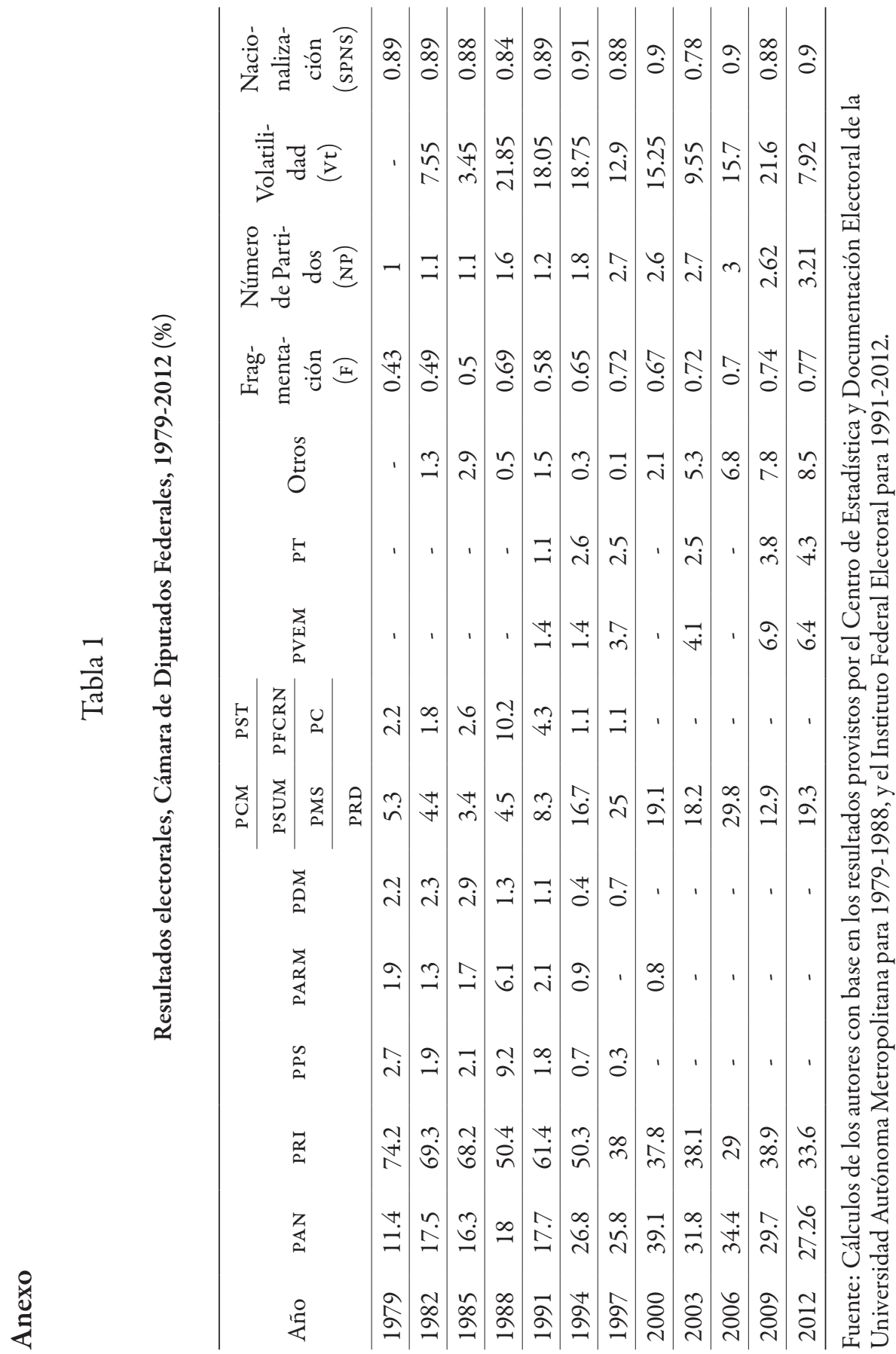




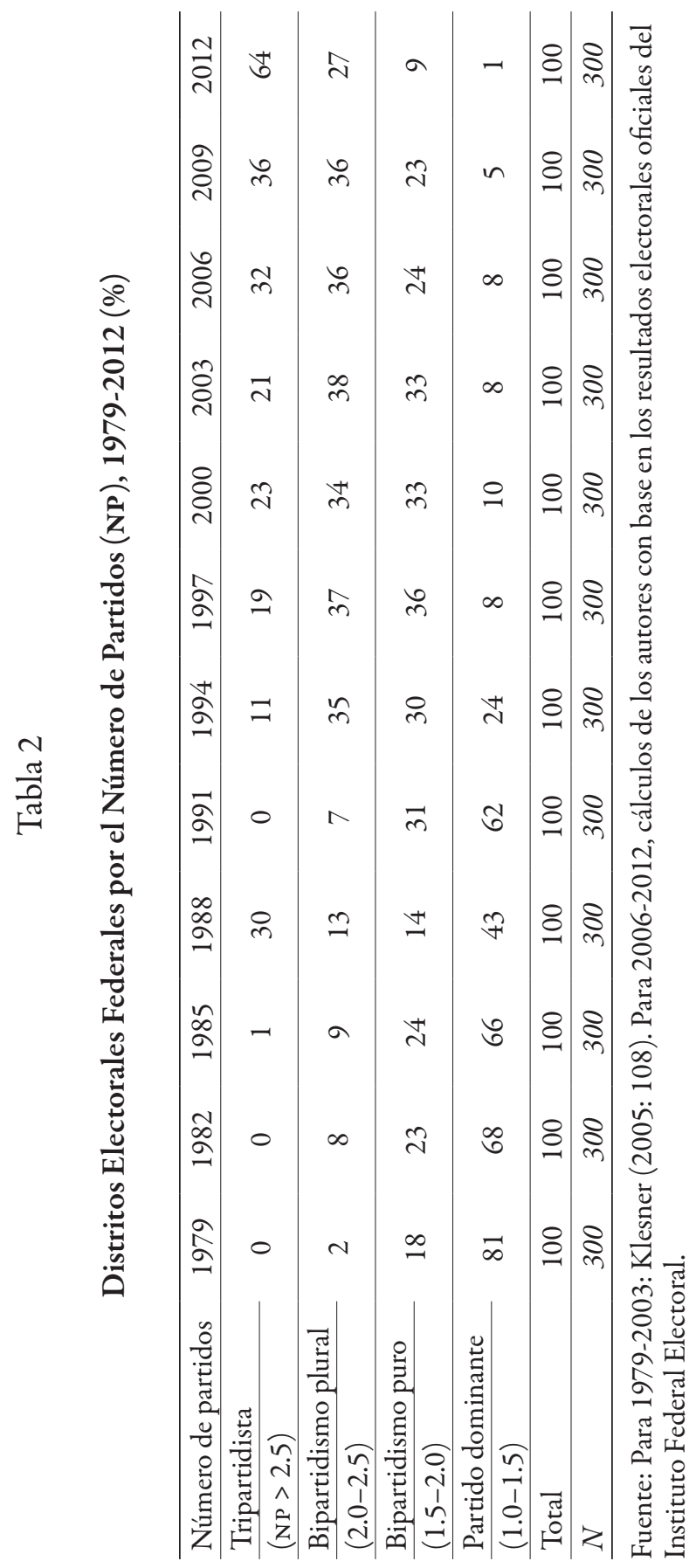


Oniel Francisco Díaz-Jiménez e Igor Vivero-Ávila. Las dimensiones de la competencia en el sistema de partidos mexicano (1979-2012)

\section{Tabla 3}

\section{Autoubicación ideológica y ubicación del partido}

\begin{tabular}{|c|c|c|c|c|c|}
\hline \multicolumn{6}{|c|}{ Legislatura LVI (1994-1997) } \\
\hline \multicolumn{3}{|c|}{ Autoubicación } & \multicolumn{3}{|c|}{ Ubicación del partido } \\
\hline Partido $(\mathrm{N})$ & Media & Desviación & Partido (N) & Media & Desviación \\
\hline PAN (28) & 6.15 & 1.62 & $\operatorname{PAN}(28)$ & 6.45 & 1.48 \\
\hline PRD (17) & 3.65 & 1.44 & PRD (17) & 3.27 & .99 \\
\hline PRI (73) & 4.94 & 1.46 & PRI $(71)$ & 5.40 & .96 \\
\hline Total (119) & 5.04 & 1.67 & Total (116) & 5.35 & 1.46 \\
\hline \multicolumn{6}{|c|}{ Legislatura LVII (1997-2000) } \\
\hline \multicolumn{3}{|c|}{ Autoubicación } & \multicolumn{3}{|c|}{ Ubicación del partido } \\
\hline Partido (N) & Media & Desviación & Partido $(\mathrm{N})$ & Media & Desviación \\
\hline $\operatorname{PAN}(31)$ & 5.90 & 1.39 & $\operatorname{PAN}(31)$ & 6.00 & .85 \\
\hline PRD (31) & 2.77 & 1.62 & PRD (31) & 3.00 & 1.43 \\
\hline PRI (59) & 5.29 & 1.46 & PRI (59) & 5.42 & 1.07 \\
\hline Total (121) & 4.80 & 1.91 & Total $(121)$ & 4.95 & 1.62 \\
\hline \multicolumn{6}{|c|}{ Legislatura LVIII (2000-2003) } \\
\hline \multicolumn{3}{|c|}{ Autoubicación } & \multicolumn{3}{|c|}{ Ubicación del partido } \\
\hline Partido (N) & Media & Desviación & Partido $(\mathrm{N})$ & Media & Desviación \\
\hline PAN (48) & 5.88 & 1.16 & $\operatorname{PAN}(47)$ & 6.38 & 1.03 \\
\hline PRD (12) & 3.08 & 1.08 & PRD (11) & 4.18 & 1.32 \\
\hline PRI $(52)$ & 4.71 & 1.44 & PRI (52) & 5.25 & 1.18 \\
\hline Total (112) & 5.04 & 1.55 & Total $(110)$ & 5.63 & 1.34 \\
\hline \multicolumn{6}{|c|}{ Legislatura LIX $(2003-2006)$} \\
\hline \multicolumn{3}{|c|}{ Autoubicación } & \multicolumn{3}{|c|}{ Ubicación del partido } \\
\hline Partido $(\mathrm{N})$ & Media & Desviación & Partido $(\mathrm{N})$ & Media & Desviación \\
\hline $\operatorname{PAN}(36)$ & 6.44 & 1.59 & $\operatorname{PAN}(36)$ & 6.94 & 1.37 \\
\hline PRD (24) & 2.82 & 1.14 & PRD (24) & 3.14 & .99 \\
\hline PRI (53) & 5.22 & 1.16 & PRI (54) & 5.61 & 1.25 \\
\hline Total (113) & 4.82 & 1.29 & Total (114) & 5.23 & 1.20 \\
\hline
\end{tabular}




\begin{tabular}{|c|c|c|c|c|c|}
\hline \multicolumn{6}{|c|}{ Legislatura LX (2006-2009) } \\
\hline \multicolumn{3}{|c|}{ Autoubicación } & \multicolumn{3}{|c|}{ Ubicación del partido } \\
\hline Partido (N) & Media & Desviación & Partido $(\mathrm{N})$ & Media & Desviación \\
\hline $\operatorname{PAN}(51)$ & 6.19 & 1.35 & $\operatorname{PAN}(51)$ & 6.66 & 1.49 \\
\hline PRD (33) & 2.25 & 1.19 & PRD (33) & 2.43 & 1.26 \\
\hline PRI (27) & 4.46 & 1.13 & PRI (27) & 4.96 & 1.09 \\
\hline Total $(111)$ & 4.30 & 1.22 & Total (111) & 4.68 & 1.28 \\
\hline \multicolumn{6}{|c|}{ Legislatura LXI (2009-2012) } \\
\hline \multicolumn{3}{|c|}{ Autoubicación } & \multicolumn{3}{|c|}{ Ubicación del partido } \\
\hline Partido $(\mathrm{N})$ & Media & Desviación & Partido (N) & Media & Desviación \\
\hline PAN (28) & 6.47 & 1.50 & $\operatorname{PAN}(28)$ & 7.41 & 1.41 \\
\hline PRD (14) & 3.57 & 1.40 & PRD (14) & 4.77 & 1.42 \\
\hline PRI (45) & 5.02 & 0.97 & PRI (41) & 5.28 & 0.81 \\
\hline Total (87) & 5.02 & 1.29 & Total (83) & 5.82 & 1.21 \\
\hline
\end{tabular}

Fuente: Elaboración propia a partir de los datos de PELA. Para la autoubicación, la pregunta que se utilizó fue: "Como recordará, cuando se habla de política se utilizan normalmente las expresiones izquierda y derecha. En esta tarjeta hay una serie de casillas que van de izquierda a derecha. ¿En qué casilla se colocaría Ud. teniendo en cuenta sus ideas políticas?”. La escala se compone del 1 al 10 donde uno es izquierda y 10, derecha. Para la ubicación del partido la pregunta que se utilizó fue: "Y, en esta misma escala ¿dónde situaría Ud. a su propio partido?”. Para una descripción más detallada del proyecto PELA, véase el sitio web: http:// americo.usal.es/oir/elites/ 


\section{Gráfico 1}

Partidismo en México, 1983-2012 (\%)

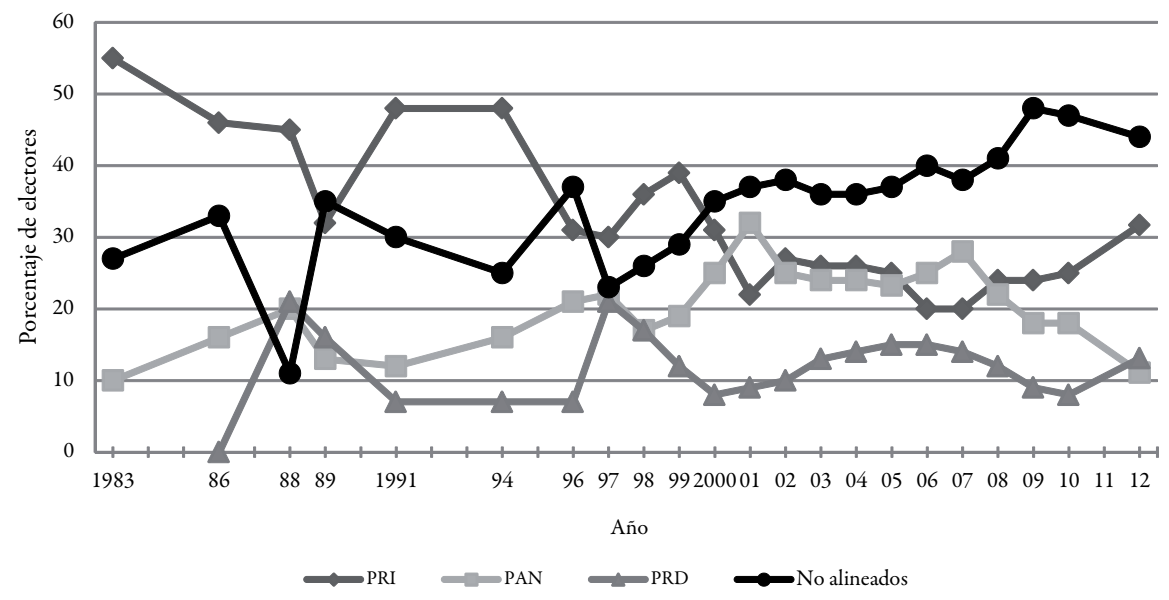

Fuentes: 1983: Encuesta de Miguel Basáñez; 1986: Encuesta New York Times, 1988: Encuesta Gallup; 1989 y 1991: Encuesta Los Angeles Times-Prospectiva Estratégica A.C.; 1994: Encuesta Belden y Russonello con Ciencia Aplicada; 1996: Encuesta Reforma-Los Angeles Times; 1997: Encuesta ITAM-Arcop; 1998-2009: Promedios anuales obtenidos a partir de encuestas trimestrales de Reforma reportados en Moreno (2012). Los porcentajes no suman 100, porque no se presenta la opción "Otro partido". La pregunta utilizada a partir de noviembre de 1999 es: "Generalmente ¿usted se considera priísta, panista o perredista?", seguida de la pregunta “ ¿Se considera muy o algo...?”. En encuestas previas se usaron variantes de pregunta sobre simpatía con algún partido político.

*Los datos del PRD para 1988 corresponden a la suma del porcentaje de identificados con los partidos que conformaron el Frente Democrático Nacional y solamente se ofrecen como un indicador de referencia. 


\section{Gráfico 2}

Fortaleza del partidismo en México, 1989-2007 (\%)

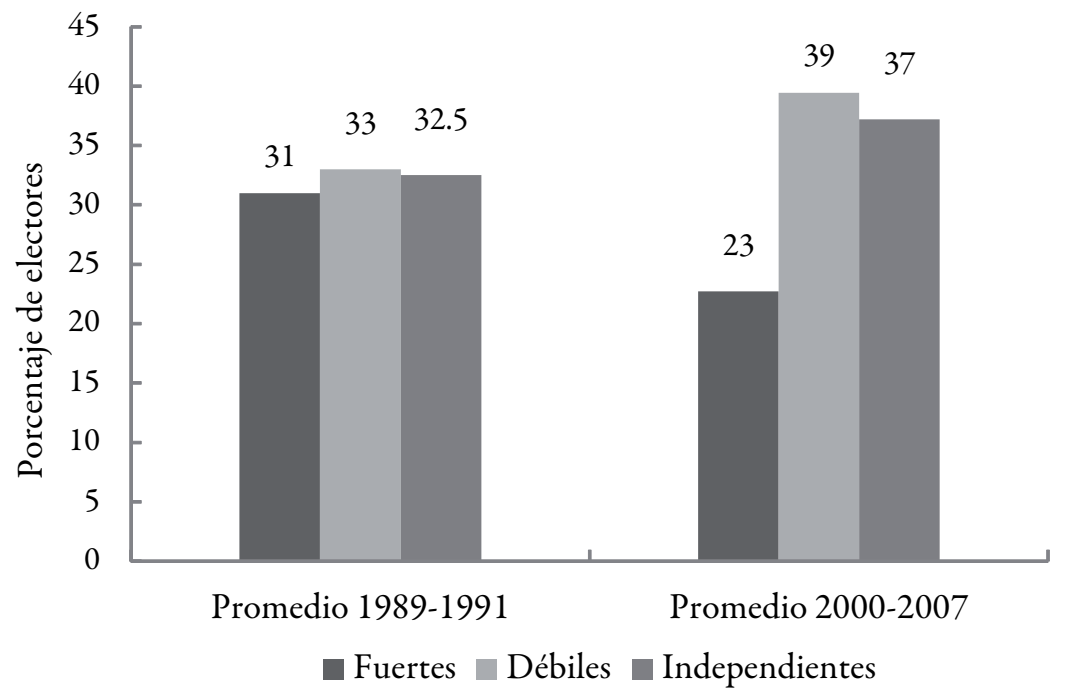

Fuente: 1989 y 1991: Encuesta Los Angeles Times-Prospectiva Estratégica A.C., 2000-2007:

Encuestas trimestrales de Grupo Reforma reportados en Moreno (2009). 


\section{Gráfico 3}

\section{Ubicación del partido y autoubicación de los legisladores en la escala izquierda- derecha (1994-2012)}

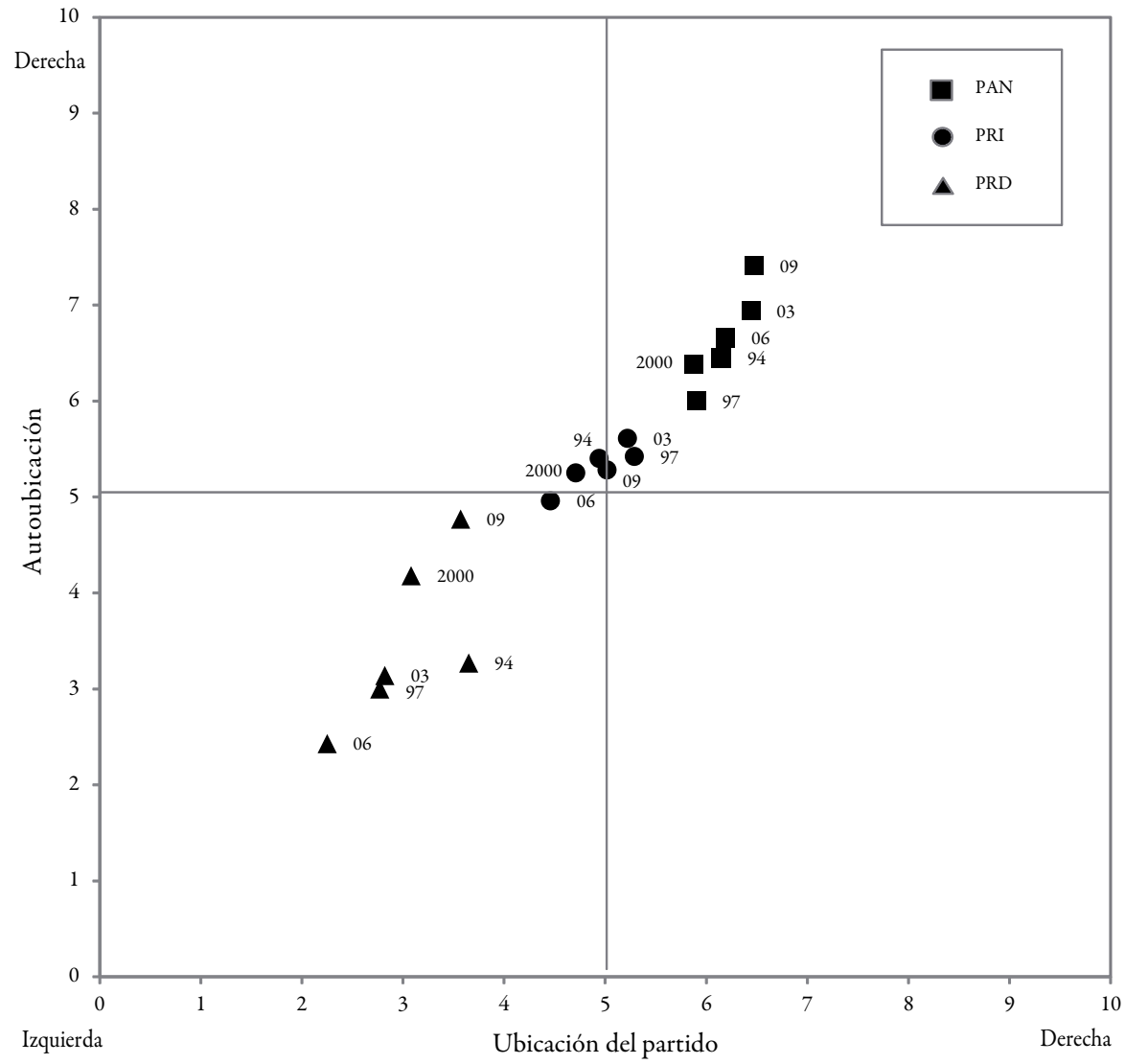

Fuente: Elaboración propia a partir de los datos de PeLA. Para la autoubicación, la pregunta que se utilizó fue: "Como recordará, cuando se habla de política se ocuparon normalmente las expresiones izquierda y derecha. En esta tarjeta hay una serie de casillas que van de izquierda a derecha. ¿En qué casilla se colocaría Ud. teniendo en cuenta sus ideas políticas?”. La escala se compone del 1 al 10, donde uno es izquierda y 10, derecha. Para la ubicación del partido la pregunta que se utilizó fue: "Y, en esta misma escala ¿dónde situaría Ud. a su propio partido?". Para una descripción más detallada del proyecto PELA véase el sitio web: http://americo.usal.es/oir/elites/. 
Oniel Francisco Díaz Jiménez. ${ }^{16}$ Doctor en Ciencia Política y Estudios Internacionales por la Universidad de Birmingham, Reino Unido. Profesorinvestigador del Departamento de Procesos Sociales/División de Ciencias Sociales y Humanidades de la Universidad Autónoma Metropolitana, Unidad Lerma. Sus principales líneas de investigación son: gobierno y política comparada, métodos cuantitativos y cualitativos de investigación, elecciones, partidos políticos y sistemas de partidos, comunicación política y opinión pública. Publicaciones recientes: Natal, Alejandro y Oniel Francisco Díaz Jiménez [coords.], Observatorios ciudadanos: Nuevas formas de participación de la sociedad, México: UAM-Lerma/Iztapalapa/Gernika (2014); Díaz Jiménez, Oniel Francisco, "La evolución de la competencia partidista en México y en el Estado de México. Un análisis comparado del cambio y la continuidad en los sistemas de partidos nacional y local (1979-2012)", en Ramiro Medrano González, Joaquín Ordoñez Sedeño y Alejandro Rafael Alvarado Granados [coords.], La elección presidencial de 2012: miradas desde el Estado de México, México: UAem/IeEm/Fontamara (2014); Díaz Jiménez, Oniel Francisco e Igor Vivero Ávila, “¿Efectos limitados o poderosos? Una Revisión a la Investigación sobre los Efectos de las Comunicaciones de Campaña en México", en Revista Debates, vol., 8, núm. 1 (2014).

Igor Vivero Ávila. ${ }^{17}$ Doctor en Ciencias Políticas por la Universidad de Salamanca, España. Profesor-Investigador de la Facultad de Ciencias Políticas y Sociales de la Universidad Autónoma del Estado de México. Miembro del Sistema Nacional de Investigadores. Sus líneas de investigación son: partidos políticos y sistemas de partidos, elecciones, instituciones legislativas. Publicaciones recientes: Vivero Ávila, Igor y Oniel Francisco Díaz Jiménez, "Los caminos hacia el multipartidismo. El cambio en el sistema de partidos mexicano”, en Héctor Tejera Gaona y Pablo Castro [coords.], Continuidades, rupturas y regresiones: las contradicciones de la democracia mexicana, México: UAM-Iztapalapa (2014); Vivero Ávila, Igor [coord.], Democracia y reformas politicas en México y América Latina, México: UaEm/IEem/IA Pem/

16 Los nombres de los autores están en orden aleatorio, ambos contribuyeron por igual en la elaboración del trabajo.

17 El autor agradece al Programa de "Estancias Postdoctorales y sabáticas al extranjero para la Consolidación de Grupos de Investigación” del Conacyt, convocatoria 2013, así como la hospitalidad del Instituto de Estudios Latinoamericanos del German Institute of Global and Area Studies (GIGA) de Hamburgo donde se realizó la estancia Sabática. En particular, al Dr. Detlef Nolte por sus atenciones. 
Miguel Ángel Porrúa (2010); Vivero Ávila, Igor, Desafiando al sistema. La izquierda politica en México, México: UAEm/Miguel Ángel Porrúa (2006).

Recepción: 22 de marzo de 2014.

Aprobación: 19 de diciembre de 2014. 
